\title{
Fuzzy-based Cluster Head Selection for Pegasis Protocol in WSN
}

\author{
Suraj Srivastava* and Dinesh Grover \\ Department of Research, Innovation and Consultancy \\ IKG Punjab Technical University, Jalandhar, Punjab, India \\ *surajsriengg@gmail.com,dineshgrover@yahoo.com
}

\begin{abstract}
A Wireless sensor network is a collection of specific sensors with an interchanges framework for observing and recording conditions at differing areas. Usually observed parameters include temperature, moistness, weight, direction of wind and so forth. A wireless sensor network (WSN) sometimes referred as wireless sensor and actuator network (WASN) [1] is spatially conveyed self-governing sensor to monitor physical or ecological situations, such as, temperature, sound, weight and so on and to helpfully go their information through the system to a fundamental area. PEGASIS is a chain based convention that gives change over LEACH calculations. In PEGASIS, everyhub discusses just with a close neighbor and rotates transmitting to the base station, accordingly diminishing the computation of vitality spent in each round. In this research work, a novel technique is proposed for cluster head selection for Pegasis, chain based routing protocol with fuzzy logic.
\end{abstract}

Keywords: Wireless Sensor Network, Pegasis, Leach, Base Station, Cluster Head, Chain Based Routing Protocol, Fuzzy Logic

\section{Introduction}

WSN is termed as wireless sensor network that consists of very large number of nodes that are connected with each other. These nodes are used to sense large amount of distinct data, interact with each other, and are computationally capable. Sensor field is the scattered area used to deploy sensors. Sensors accumulate data from surroundings and transmit it to the base station via multi-hops. Base station also called as the sink, usually interacts with the client via a web connection or a satellite.

WSN have gained much attention in recent years due to diverse and a wide range of applications. Wireless sensor networks can be categorized into two types on the basis of its applications, i.e., monitoring and tracking. Monitoring applications consists of inner and outer environmental monitoring like development and industry, structure and seismic, physical condition, and control monitoring. Tracking applications consists of people, vehicles, tracking objects, and animals [1].

WSN is a promising field for both industry and researchers due to its wide variety of applications. The sensor nodes use most of their energy to interact with other nodes. Hence, routing protocol plays a vital role to transmit network data while reducing consumption of energy. The chain-based routing technique is better than other techniques. Pegasis is a chain-based routing protocol having some deficiencies along with threshold uncertainty during chain building [2].

Received (January 6, 2018), Review Result (March 6, 2018), Accepted (March 13, 2018)

${ }^{*}$ Corresponding Author 


\section{Prior Work}

Asif et al., concentrated on the QoS fulfillment in WSNs, essentials of QoS bolster in WSNs, and all the more imperatively challenge, prerequisites of QoS at each layer. This paper likewise looked into the QoS conventions and classify the QoS mindful conventions and expound their advantages and disadvantages and talked about the QoS parameters concerning every convention execution parameters. A study and far reaching talk on QoS mindful conventions of WSNs are displayed including their qualities and confinements. At long last, this paper likewise studied some computational insight (CI) methods and the fundamental necessities of such systems [1].

Marhoon et al., displayed the DCBRP and concentrated on the Chain-Head Selection system (CHS). The CHS instrument is in charge of choosing the chain-head hub in each bunch in the system. This choice relies upon the capacities of the hubs. At the end of the day, the CHS factor measures the capacity of a hub to convey the system information with least vitality utilization from its residual vitality. The hub that has the littlest estimation of CHS factor will be chosen by the BS to end up a $\mathrm{CH}$ for this round. The vitality utilization is an essential metric for the execution assessment of the WSN. It is influenced by the conduct of the CHS instrument and in this way it is contrasted and the CCM and TSCP. The outcomes demonstrate that the DCBRP beats the CCM and TSCP as far as both hub vitality utilization and $\mathrm{CH}$ vitality utilization [2].

Sen et al., EEPB (Energy-Efficient PEGASIS-Based convention) is a chain-based convention which has certain drawbacks including the vulnerability of limit received when constructing a chain, the certainty of long connection (LL) while esteeming limit improperly and the non-ideal race of pioneer hub. Going for these issues, an enhanced vitality effective PEGASIS-based convention (IEEPB) is proposed in this paper. IEEPB embraces new strategy to fabricate chain, and uses weighting strategy while choosing the pioneer hub, that is allotting each hub a weight to speak to its proper level of being a pioneer which thinks about leftover vitality of hubs and separation between a hub and base station (BS) as key parameters [3].

Prathap et al., analysed the wireless sensor network Applications, their huge QOS needs, and routing conventions which fulfill the QOS needs. Some other applications that have similar QOS requirements may utilize the steering convention that fulfills the QOS. Any calculation which fulfills the QOS parameters might be connected to the application space [4].

Yu et al., characterized existing conventions based on various outline criteria and after that displayed a study of the best in class directing conventions in this territory. Remote sensor systems with versatile sinks, mWSNs, have pulled in a great deal of consideration as of late. This is on account of sink portability can extraordinarily ease the hotspot issue in WSNs and further delay the system lifetime. Be that as it may, sink versatility additionally causes startling changes in organize topology and information directing ways, which can to a great extent influence the directing execution in such systems. Plan of productive directing conventions for mWSNs has been a basic issue, and much work has been done in this perspective [5].

Anjali et al., analyzed the grouping of steering conventions with examination. This paper likewise considered the different security dangers on directing conventions of remote sensor systems and a few guard strategies are additionally said. Steering conventions are utilized for correspondence in the system. Steering conventions find the fitting way to transmit the information and keep up the courses in the system. Numerous steering strategies in WSNs have been proposed. In any case, without security, the utilization of these conventions winds up constrained. Giving a secure correspondence between hubs is likewise an imperative undertaking [6].

Zhang et al., classified existing steering conventions for Wireless Sensor Network, while correlation and examination look into are likewise given on course structure, 
vitality utilization, power, expansibility, hub versatility, information combination innovation, regardless of whether QoS is bolstered and augmenting the system lifecycle of all sorts of steering conventions. Toward the finish of this paper, a reproduction examine is made with NS2 organize recreation programming on the dynamic grouping procedure of LEACH conventions, which is a run of the mill WSN steering convention. The reproduction comes about demonstrate that the irregular group head choosing technique in LEACH convention can't guarantee the quantity of group heads totally equivalent to the anticipant ideal one amid the dynamic grouping process, and it likewise exists that the separations between group heads are excessively close or sensors of a few locales are too a long way from their group heads [7].

Ennaji et al., studied wireless sensor networks all through various chose articles, papers, and online assets. A decent comprehension of sensor systems and remote interchanges is the fundamental learning result of this consider. Particularly, the examination focuses on directing in sensor arranges, and is bolstered by a recreation of a sensor organize application performed with Network Simulator. Previously reproducing, a cautious investigation of accessible test systems is directed as well. Once the devices are accessible, usage and recreation takes after. The recreation centers around finding the best steering convention, as far as postponement and dropped bundles, as a supplement for the investigation. The conventions considered are AODV and DSDV [8].

\section{The Proposed Work}

In this research work, a novel technique is proposed for cluster head on the basis of Pegasis, chain based routing protocol with fuzzy logic. PEGASIS is the ventured forward convention in which best one hub is chosen as head hub which sends the combined information to the BS in advance with round. Every hub imparts best with a close neighbor and alternates transmitting to the base station. The key idea in PEGASIS is to shape a chain some of the sensor hubs all together that every hub will get hold of from and transmit to a nearby neighbor. The steps to implement the proposed technique are:

1) Start energy, number of nodes, and location of base station for the network.

2) To construct the chain start broadcasting of message from the base station to each node to obtain the information of network such as the distance of each node from the base station, distance between other nodes, ids etc.

3) Search for extreme node from the base station utilizing bubble sort approach and initialize building of chain from that node.

4) Compute the gap between the alive nodes and then connect them to the end node. Likewise do for other nodes also.

5) Replicate this process to create the chain for all the nodes.

6) Select the node that will interact with the base station from the constructed chain utilizing Fuzzy Logic i. e., searching the node that has maximum fitness value than all the other nodes.

7) This node will send the information to the base station

The evaluation parameters considered for evaluating the performance of the proposed system are:

a) Residual Energy

b) Dead nodes and Alive nodes (Network Lifetime)

c) Packets to Base Station 


\section{Fuzzy Inference System}

Fuzzy inference framework attracts contributions to yields utilizing fuzzy logic. It outfits the fuzzy logic in four stages: Fuzzification, Rule assessment, Aggregation and Defuzzification. The fuzzy inference system consists of four parts:

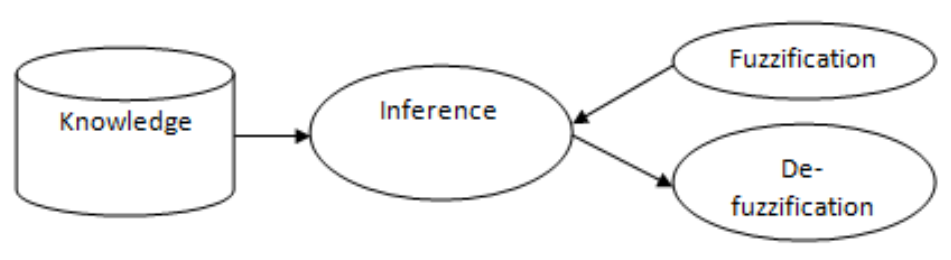

Figure 1. FIS Architecture

In FIS architecture, knowledge base is used to store IF-THEN rules, inference is a engine that recreates the human thinking process by making fuzzy inference on the sources of info and IF-THEN rules, fuzzification module changes the framework inputs, which are fresh numbers, into fuzzy sets. This is finished by applying a Fuzzification work, defuzzification module changes the fuzzy set acquired by the derivation motor into a fresh esteem.

In the proposed framework, we accept that hubs of remote sensor system can get their coordinate. System has three sections, three Fuzzification works, an inference motor (incloses 25 rules) and a Defuzzification module.

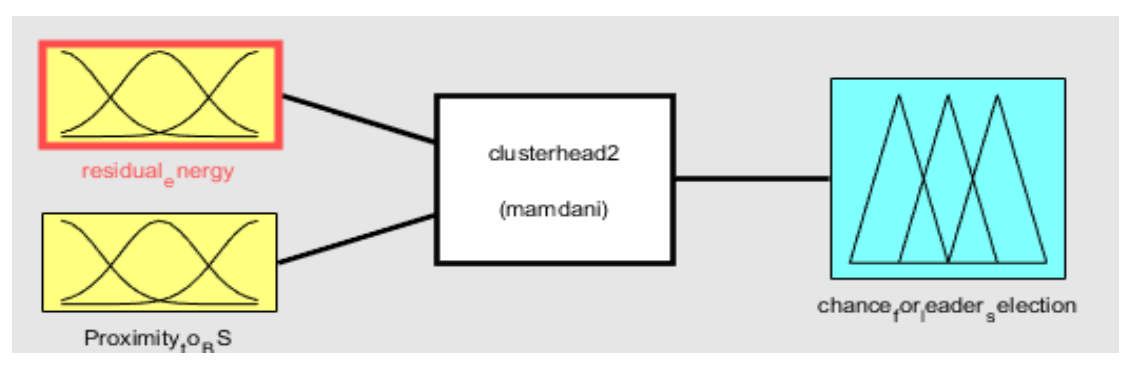

Figure 2. Fuzzy Inference System

\section{Fuzzification}

We accept that two characteristics of the hubs are required to devise the pioneer choice. Two info capacities are utilized to change the frameworks contributions to fuzzy sets in particular, remaining vitality of hub and nearness of a hub to the base station. Each info work has five participation works that portray the level of the enrollment work and furthermore outline the relationship among the information capacities is more numerical. Table 1 demonstrates the input capacities.

Table 1. Input Functions

\begin{tabular}{|c|c|c|l|c|c|}
\hline Input & \multicolumn{5}{|c|}{ Membership } \\
\hline $\begin{array}{c}\text { Residual } \\
\text { Energy }\end{array}$ & $\begin{array}{c}\text { Very Low } \\
\text { (VL) }\end{array}$ & Low (L) & Medium (M) & High (H) & $\begin{array}{c}\text { Very High } \\
\text { (VH) }\end{array}$ \\
\hline $\begin{array}{c}\text { Proximity to } \\
\text { Base Station }\end{array}$ & $\begin{array}{c}\text { Very Near } \\
\text { (VN) }\end{array}$ & Near (N) & Medium (M) & Far (F) & $\begin{array}{c}\text { Very Far } \\
\text { (VF) }\end{array}$ \\
\hline
\end{tabular}

The yield work is comprises of 9 participation capacities. Higher number of enrollment capacities is utilized in light of the fact that the contrasts of significance of the sources of info can be reflected all the more plainly [9,21]. Table 2 portrays the yield capacities. The 
three Fuzzification capacities (remaining energy, Proximity to BS, and likelihood of being leader) are appeared in Figure 3.

Table 2. Output Functions

\begin{tabular}{|c|c|}
\hline Output & Membership Function \\
\hline $\begin{array}{c}\text { Probability of } \\
\text { being leader }\end{array}$ & $\begin{array}{c}\text { Very Weak (VW) Weak (W) Little Weak (LW) Lower Medium (LM) } \\
\text { Medium (M) Higher Medium (HM) Little Strong (LS) Strong (S) Very } \\
\text { Strong (VS) }\end{array}$ \\
\hline
\end{tabular}
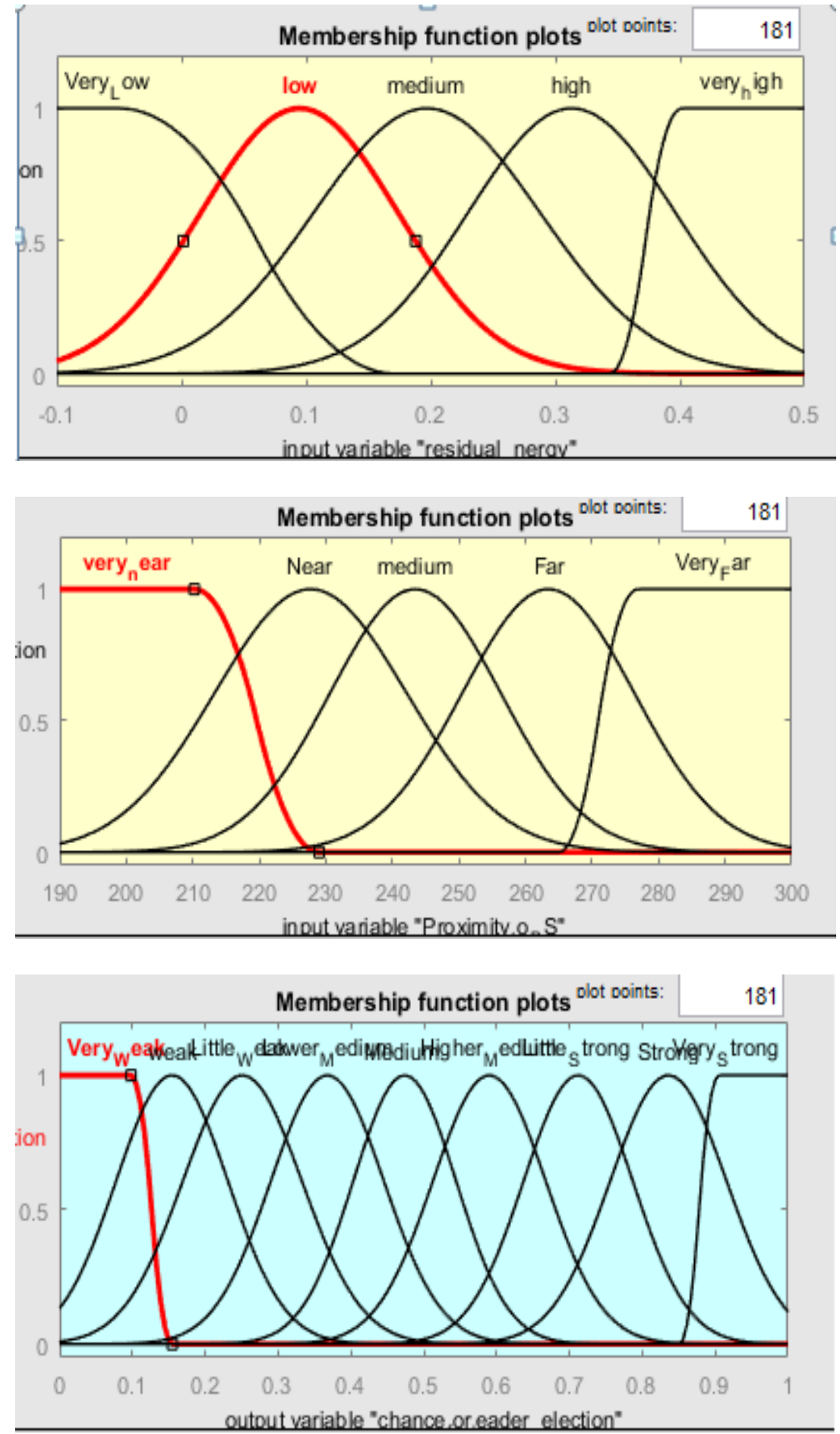


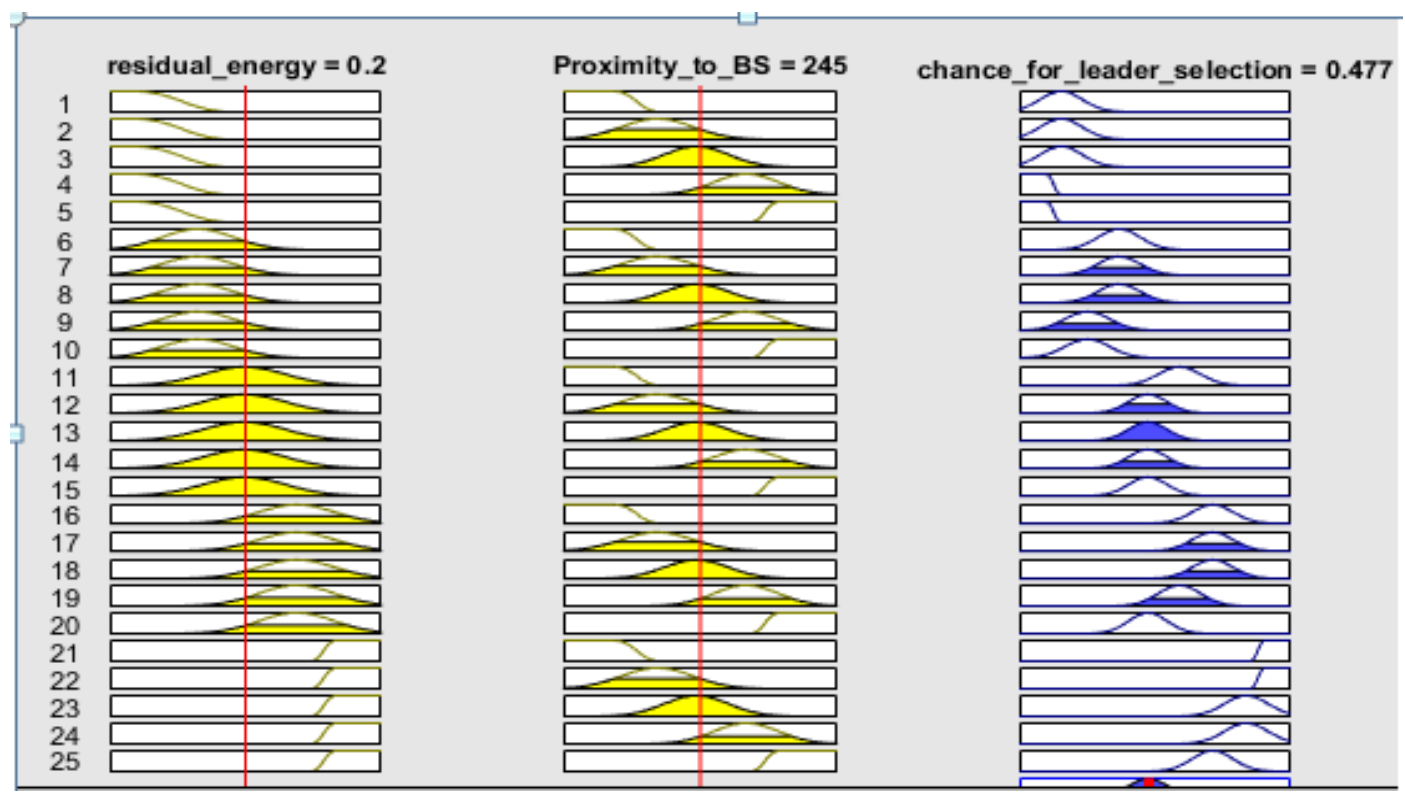

Figure 3. Fuzzification Functions (Residual Energy, Proximity to BS, Probability of being Leader)

\section{Knowledge Base}

The framework comprises of 25 manages in the fuzzy surmising. The type of the standards is: IF A and B THEN C, where A, B, C speak to battery lingering vitality, closeness to BS and Probability of being pioneer. The tenets are appeared in Table 3 .

Table 3. Rules

\begin{tabular}{|c|c|c|}
\hline Residual Energy & Proximity to Base Station & Probability \\
\hline Very Low & Very Near & Weak \\
\hline Very Low & Near & Weak \\
\hline Very Low & Medium & Weak \\
\hline Very Low & Far & Very Weak \\
\hline Very Low & Very Far & Very Weak \\
\hline Low & Very Near & Lower Medium \\
\hline Low & Near & Lower Medium \\
\hline Low & Medium & Lower Medium \\
\hline Low & Far & Little Weak \\
\hline Low & Very Far & Little Weak \\
\hline Medium & Very Near & Higher Medium \\
\hline Medium & Near & Medium \\
\hline Medium & Medium & Medium \\
\hline Medium & Far & Medium \\
\hline Medium & Very Far & Medium \\
\hline High & Very Near & Little Strong \\
\hline High & Near & Little Strong \\
\hline High & Medium & Little Strong \\
\hline High & Far & Higher Medium \\
\hline High & Very Far & Medium \\
\hline Very High & Very Near & Very Strong \\
\hline Very High & Near & Very Strong \\
\hline Very High & Medium & Strong \\
\hline Very High & Far & Strong \\
\hline Very High & Very Far & Little Strong \\
\hline
\end{tabular}




\section{Defuzzification}

A Defuzzification technique is required to get fresh esteems subsequent to conglomerating the conclusions from each run the show. One of the most acknowledged Defuzzification strategies is the Centroid, which restores the focal point of the region under the fuzzy set acquired from accumulation of conclusions. We utilize equation G(i) to get the estimation of the likelihood:

$$
G(i)=\frac{\sum_{j}^{n}=1 X_{j} \cdot u\left(X_{j}\right)}{\sum_{j}^{n}=1 u\left(X_{j}\right)}
$$

Every hub of the WSN figures an esteem G(i) through the above framework. Each hub gets an irregular number between 0 and 1 . All hubs are orchestrated based on probabilities; the hub with the most astounding likelihood is chosen as pioneer for that round.

\section{Experiments and Results}

\subsection{Simulation and Analysis}

The proposed methodologyis implementedwith the help ofMATLAB and fuzzy Logics is implemented using Fuzzy Logics Toolbox of MATLAB. Theperformance parameters of the proposed technique have been illustrated in the following figures Figure 4, Figure 5, Figure 6, and Figure 7. And comparison between Pegasis and proposed Pegasis with Fuzzy logics has been made in these figures.

Table 4. Simulation Parameters

\begin{tabular}{|c|c|}
\hline Parameter & Value \\
\hline $\mathrm{WSN}$ area $/ \mathrm{m}^{2}$ & $100 \times 100$ \\
\hline Number of Nodes & 100 \\
\hline Base Station Location & $(50 \mathrm{~m}, 50 \mathrm{~m})$ \\
\hline Initial energy/J & 0.5 \\
\hline $\mathrm{E}_{\text {elec }} /\left(\mathrm{nJ} \cdot \mathrm{bit}^{-1}\right)$ & $50 \times 10^{\wedge}-9$ \\
\hline $\mathrm{E}_{\mathrm{fs}} /\left(\mathrm{pJ} .\left(\text { bit.m }{ }^{2}\right)^{-1}\right)$ & $10 \times 10^{\wedge}-12$ \\
\hline $\mathrm{E}_{\mathrm{mp}} /\left(\mathrm{pJ} .\left(\text { bit.m } \mathrm{m}^{4}\right)^{-1}\right)$ & $0.0013 \times 10^{\wedge}-12$ \\
\hline $\mathrm{E}_{\text {fusion }} /\left(\mathrm{nJ} .\left(\mathrm{bit}^{-1} \mathrm{~m}^{-1}\right)\right.$ & $5 \times 10^{\wedge}-9$ \\
\hline Data packet size/B & 2000 \\
\hline
\end{tabular}

The above table shows the simulation parameters used for implementation of the proposed technique such as, wireless sensor network area, number of nodes, location of base station, initial energy, and so on.

\subsection{Comparison based on Dead Nodes}

This section presents the comparison of the proposed Pegasis with fuzzy and Pegasis on the basis of dead nodes. 


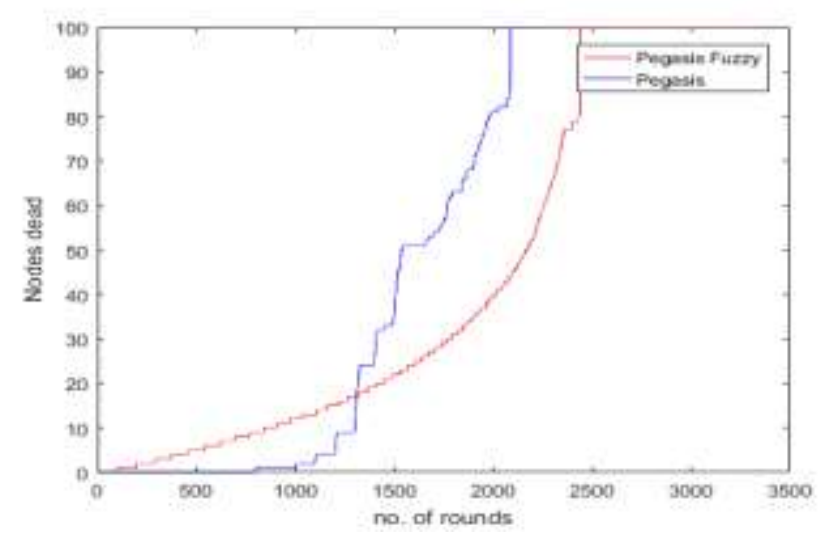

Figure 4. Dead Nodes of the Proposed Pegasis with Fuzzy and Pegasis Comparison

Above figure shows the comparison of the proposed technique pegasis with fuzzy with the existing technique pegasis based on dead nodes. It is clear from the above figure that the proposed technique has less dead nodes as compared to the existing technique.

\subsection{Comparison based on Residual Energy}

This section presents the comparison of the proposed Pegasis with fuzzy and Pegasis on the basis of residual energy.

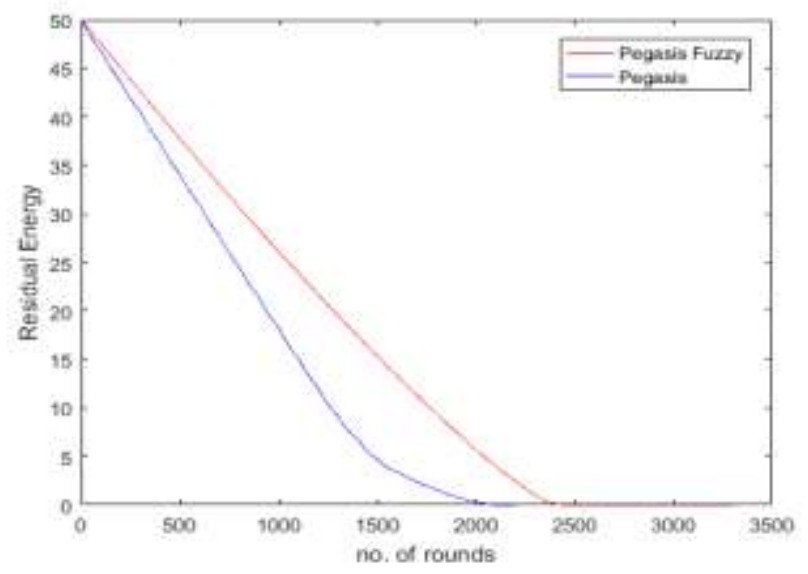

Figure 5. Residual Energy of the Proposed Pegasis with Fuzzy and Pegasis Comparison

Above figure shows the comparison of the proposed technique pegasis with fuzzy with the existing technique pegasis based on residual energy. It is clear from the above figure that the proposed technique consumes less energy as compared to the existing technique.

\subsection{Comparison based on Alive Nodes}

This section presents the comparison of the proposed Pegasis with fuzzy and Pegasis on the basis of alive nodes. 


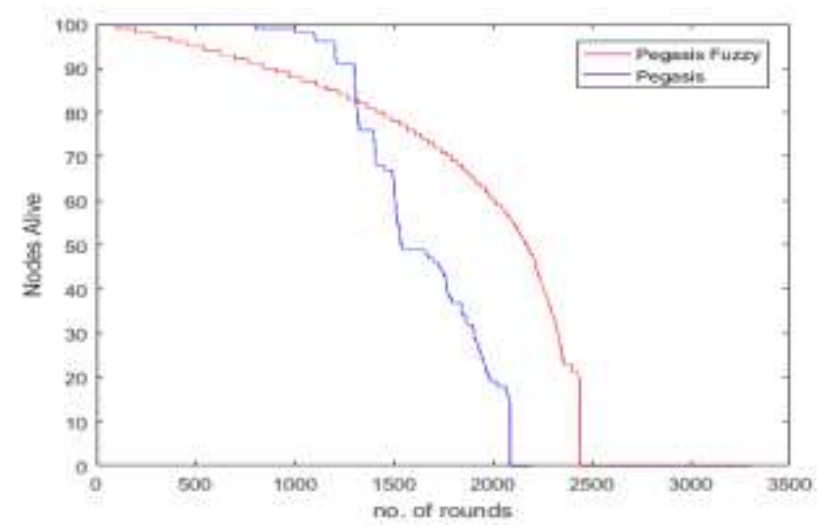

Figure 6. Alive Nodes of the Proposed Pegasis with Fuzzy and Pegasis Comparison

Above figure shows the comparison of the proposed technique pegasis with fuzzy with the existing technique pegasis based on alive nodes. It is clear from the above figure that the proposed technique has more number of alive nodes as compared to the existing technique.

\subsection{Comparison based on Packets to Base Station}

This section presents the comparison of the proposed Pegasis with fuzzy and Pegasis on the basis of packets to base station.

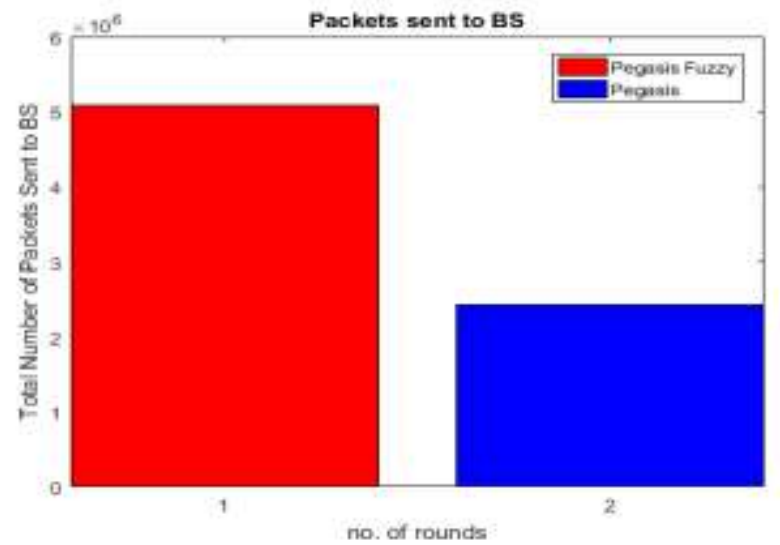

Figure 7. Packets to Base Station of the Proposed Pegasis with Fuzzy and Pegasis Comparison

Above figure shows the comparison of the proposed technique pegasis with fuzzy with the existing technique pegasis based on packets to base station. It is clear from the above figure that the proposed technique has more throughput as compared to the existing technique.

\section{Conclusion}

In this research, a novel technique is proposed for cluster head on the basis of Pegasis, chain based routing protocol with fuzzy logic. The proposed methodology is implemented with the help of MATLAB and fuzzy Logic is implemented using Fuzzy Logics Toolbox of MATLAB. The proposed technique is compared with the existing technique on the basis of dead nodes, residual energy, alive nodes, and packets to base station. The 
proposed approach gives less number of dead nodes and more number of alive nodes as compared to the previous technique, it also consumes less energy and hence provides better throughput than the existing technique. Experimental results demonstrate that the proposed technique pegasis with fuzzy outperforms the existing pegasis technique.

\section{References}

[1] M. Asif, S. Ullah Khan, R. Ahmad and M. Sohail, "Quality of Service of Routing Protocols in Wireless Sensor Networks: A Review", IEEE, (2016).

[2] H. Abdulameer Marhoon, M. Mahmuddin and S. Awang Nor, "DCBRP: a deterministic chain-based routing protocol for wireless sensor networks", Springer, vol. 5, no. 1, (2016).

[3] F. Sen, Q. Bing and T. Liangrui, "An Improved Energy-Efficient PEGASIS-Based Protocol in Wireless Sensor Networks", IEEE Eighth International Conference on Fuzzy Systems and Knowledge Discovery (FSKD), (2011), pp. 2230-2233.

[4] U. Prathap, P. Deepa Shenoy and K. R. Venugopal, "Wireless Sensor Networks Applications and Routing Protocols: Survey and Research Challenges", IEEE International Symposium on Cloud and Services Computing, (2012), pp. 49-56.

[5] S. Yu, B. Zhang, C. Li and H. T. Mouftah, "Routing Protocols for Wireless Sensor Networks with Mobile Sinks: A Survey", IEEE, (2014), pp. 150-157.

[6] S. Anjali and M. Sharma, "Wireless Sensor Networks: Routing Protocols and Security Issues", IEEE, (2014).

[7] J. Zhang, W. Li, D. Cui, X. Zhao and Z. Yin, "The NS2-based Simulation and Research on Wireless Sensor Network Route Protocol", IEEE, (2009).

[8] R. Ennaji and M. Boulmalf, "Routing in Wireless Sensor Networks", IEEE, (2009).

[9] J. Wan, D. Yuan and X. Xu, “A Review of Routing Protocols in Wireless Sensor Networks", IEEE, pp. 1-4.

[10] S. Dai, X. Jing and L. Li, "Research and Analysis on Routing Protocols for Wireless Sensor Networks", IEEE, (2005), pp. 407-411.
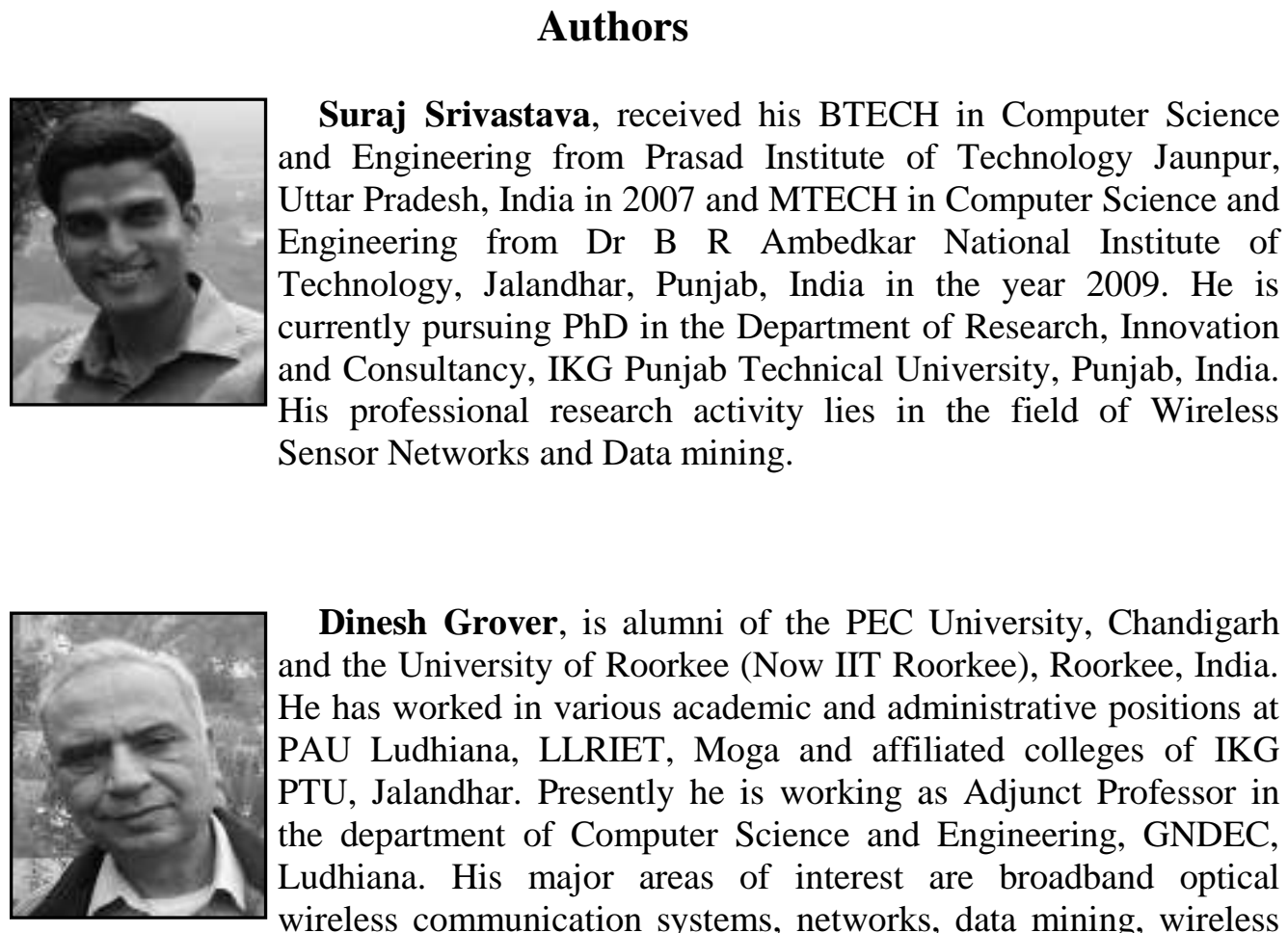

Dinesh Grover, is alumni of the PEC University, Chandigarh and the University of Roorkee (Now IIT Roorkee), Roorkee, India. $\mathrm{He}$ has worked in various academic and administrative positions at PAU Ludhiana, LLRIET, Moga and affiliated colleges of IKG PTU, Jalandhar. Presently he is working as Adjunct Professor in the department of Computer Science and Engineering, GNDEC, Ludhiana. His major areas of interest are broadband optical wireless communication systems, networks, data mining, wireless sensor networks and computer communication. He has published many research papers in the International/National Journals/Conferences. 